\title{
Safeguarding biodiversity: what is perceived as working, according to the conservation community?
}

\author{
Colin A. Chapman, Anneke Deluycker, Rafael A. Reyna-Hurtado \\ Juan Carlos Serio-Silva, Thomas B. Smith \\ Karen B. Strier and Tony L. Goldberg
}

\begin{abstract}
Dramatic increases in human populations and per capita consumption, climate change, overexploitation of marine and freshwater resources, and deforestation have caused a litany of negative consequences for biodiversity. Such doom-and-gloom scenarios are widely known, frequently cited and frankly depressing. Although accurate assessments of threats have clear value for intervention planning, we believe there is also a need to reflect on successes. Such reflection provides balance to negative scenarios and may shift attention towards constructive, positive action. Here we use a systematic evaluation of 90 success stories provided by conservation scientists and practitioners to explore the characteristics of the projects perceived as being associated with success. Success was deemed to have occurred for $19.4 \%$ of the projects simply because an event had occurred (e.g. a law was passed) and for $36.1 \%$ of projects quantitative data indicated success (e.g. censuses demonstrated population increase). However, for most projects $(63.9 \%)$ there was no evaluation and success was defined by the subjective opinion of the respondent. Conservation community members viewed successful projects most often as those being long-term (88\%), small in spatial scale $(52 \%)$, with a relatively low budget (68\%), and involving a protectionist approach alone or in combination with another approach. These results highlight the subjectivity of definitions of success in conservation but also the
\end{abstract}

Colin A. Chapman (Corresponding author) School of Environment and Department of Anthropology, McGill University, Montreal, Quebec, Canada, and Wildlife Conservation Society, Bronx, New York, USA

E-mail colin.chapman@mcgill.ca

Anneke DeLuycker Smithsonian-Mason School of Conservation, Smithsonian Conservation Biology Institute, Front Royal, Virginia, USA

Rafael A. Reyna-Hurtado El Colegio de la Frontera Sur, Campeche, Mexico

Juan Carlos Serio-Silva Red de Biología y Conservación de Vertebrados, Instituto de Ecología AC, Xalapa, Veracruz, Mexico

Thомаs B. Sмiтн Department of Ecology and Evolutionary Biology, and Center for Tropical Research, Institute of the Environment and Sustainability, University of California, Los Angeles, California, USA

KAREN B. Strier Department of Anthropology, University of WisconsinMadison, Madison, Wisconsin, USA

Tony L. Goldberg Department of Pathobiological Sciences, University of Wisconsin-Madison, Madison, Wisconsin, USA

Received 7 March 2014. Revision requested 23 May 2014.

Accepted 29 August 2014. First published online 17 December 2014. characteristics of conservation efforts that the conservation community perceives as indicative of success.

Keywords Biodiversity loss, conservation approach, development, evaluation of success

\section{Introduction}

$\mathrm{B}$ iodiversity conservation is a growing priority among B the world's governments and people. This is exemplified by the 1992 UN Convention on Biological Diversity, one of the most widely ratified treaties, with over 193 signatories committed to substantially reducing biodiversity loss. Public interest in biodiversity is also increasing globally. For example, WWF has more than 5 million supporters (Rands et al., 2010) and National Geographic Society media are viewed by c. 400 million people each month (John Francis, pers. comm.). Nevertheless, recent surveys of the public's priorities indicate that environmental issues rank well below problems such as terrorism, health care and the economy (Novacek, 2008). Furthermore, the recent increased interest in the environment is a result of concerns about climate change, such that interest in problems such as biodiversity loss is fading (Novacek, 2008). Such a shift in public concern is exacerbated by the fact that the media often portray the science behind solutions to environmental problems as being overly complex (Novacek, 2008), as well as by a portrayal of conservation using doom-and-gloom scenarios that engender despair (Beever, 2000; Garcia \& Grainger, 2005; Garnett \& Lindenmayer, 2011). This leaves an unfortunate impression that environmental situations are dire and there is little that can be done. Given the serious nature of biodiversity loss, scientists should not only generate data but also have an active voice in stating whether these doom-and-gloom scenarios are accurate and what positive approaches can mitigate threats.

There are ample doom-and-gloom statistics. For example, during 2000-2010 c. 130 million ha of forest disappeared worldwide (FAO, 2010); this represents c. $3.2 \%$ of the total forest area in 2000 and is larger than Peru or almost three times the area of Sweden. Marine and freshwater biodiversity are under increasing pressure from overexploitation and habitat degradation (Jackson et al., 2001; McClenachan et al., 2012). For example, one-third of the world's reef- 
building corals are thought to be at risk of extinction as a result of climate change and local anthropogenic impacts.

Running counter to such doom-and-gloom statistics are positive developments with respect to protected areas. Since 1992 the coverage of protected areas has grown steadily, increasing annually by a mean of $2.5 \%$ in total area and $1.4 \%$ in number of sites (Butchart et al., 2010; Rands et al., 2010). By 2006, protected areas covered 24 million $\mathrm{km}^{2}$, in 133,000 designated areas (Butchart et al., 2010; Rands et al., 2010). However, these positive developments need to be viewed from a balanced perspective (Andam et al., 2008; Joppa et al., 2008; Joppa \& Pfaff, 2009, 2010). For example, it is estimated that $20 \%$ of vertebrate taxa recognized as threatened by the IUCN are not in any protected area (Rodrigues et al., 2004). Also, although protected areas are generally effective in protecting land from being cleared, they are less effective at eliminating logging, human-created fire and bushmeat hunting (Oates, 1996; Bruner et al., 2001; Chapman \& Peres, 2001; Hartter et al., 2011), or protecting the processes that generate and maintain biodiversity (Smith et al., 1993). Furthermore, about half of all protected areas are experiencing an erosion of biodiversity (Laurance et al., 2012). Also, it is estimated that more than two-thirds of critical sites for biodiversity have incomplete or no protection (Butchart et al., 2010).

Although we support the need for accurate assessments of threats to biodiversity, we also believe that the conservation community should not focus so persistently on doom-and-gloom scenarios. Identifying conservation success stories may help provide a much-needed counterbalance that engenders positive thinking and ultimately more effective action (Garnett \& Lindenmayer, 2011). Describing how the conservation community itself perceives success will help generate hypotheses as to how to approach conservation most effectively in the future, and we believe it will encourage the public, including voters, to be more interested in biodiversity conservation. Here we use a systematic evaluation of anecdotes or stories (Bates \& Byrne, 2007) to explore what characteristics the conservation community itself perceives as being associated with success.

\section{Surveying the conservation community}

Evaluating the effectiveness of many of the common approaches to conservation is a difficult task, despite the development of a number of new techniques (Andam et al., 2008; Kapos et al., 2008, 2009; Joppa \& Pfaff, 2009, 2010; Butchart et al., 2010). This difficulty stems from several factors, including project goals that are not clearly stated, lack of monitoring, absence of controls where no action was taken, and general paucity and incompatibility of data across projects. Given these limitations, our goal is to present information on what the conservation community itself perceives as being associated with success. We fully acknowledge the subjectivity of this approach and recognize that it makes important assumptions and has potential biases.

Our study was guided by three important considerations. Firstly, we assumed that academics and conservation practitioners do not frequently publish information about conservation successes. We made this assumption because the information necessary to evaluate a project often takes a decade or more to collect. Also, quantitative evaluation of conservation projects was not a priority a decade or more ago, when many conservation projects were established (Solomon, 2007). This has led to the perception that the insight gained over time by a single individual or small group of collaborating individuals cannot be generalized (i.e. it is a case study), and many journals in the field of conservation biology have policies indicating that case studies are not prioritized. Secondly, surveys evaluating conservation successes vs failures face methodological challenges. For example, survey results from personnel working in protected areas generally lack independent verification. Thus, not surprisingly, surveys asking whether protected areas are successful tend to consist of emphatic 'yes' (Liu et al., 2001; Curran et al., 2004; Román-Cuesta \& Martínez-Vilalta, 2006) and emphatic 'no' replies (Oliveira et al., 2007; reviewed by Joppa et al., 2008; Laurance et al., 2012). Thirdly, it was our opinion that the academic and conservation community perceives itself as being over-surveyed; thus response rates to a structured questionnaire would be low and biased.

With these issues in mind we adopted an alternative approach and evaluated what characteristics of conservation programmes members of the conservation community itself perceived as being associated with success. We first sent an e-mail to individuals known personally by one of the authors and made a simple request: outline one or two situations where a project has made significant conservation advances and explain why it was a success. We asked for the information to be relayed in story form and suggested that 300 words was sufficient. We also invited each respondent to offer the names of two people they thought could contribute another conservation success story. We only approached these secondary contacts if the original responder specifically stated that his or her name could be used when we made the subsequent request. We asked an open-ended question under the assumption that this would be most likely to elicit information about non-traditional conservation approaches. Because we knew some responses would be controversial and potentially damaging if linked to the respondents, we guaranteed anonymity. For the Latin American conservation community the e-mails were sent in Spanish and replies were subsequently translated into English. We stopped sending requests after 200 invitations were sent. Our efforts resulted in 66 conservationists relaying 90 stories. 
A potential bias of this approach is that the individuals contacted might not be representative of the conservation community as a whole. To limit this bias we endeavoured to contact as diverse a range of potential respondents as possible, including individuals from different fields (e.g. veterinary medicine, behaviour, ecology, evolutionary biology, anthropology, economics), working in different regions of the world, associated with different types of agencies, focusing on different types of taxa (e.g. corals, insects, birds, mammals, fish) and ecosystems (e.g. marine, terrestrial, tropical, temperate), and having worked on projects using a diversity of approaches. This approach facilitated the acquisition of different perspectives, although we acknowledge that biases are inevitable.

We categorized projects with respect to five features. (1) We assessed projects according to their duration: short-term $(<3$ years; a typical grant cycle); medium-term (4-10 years; often the time invested by a single individual), and longterm $(>10$ years; often requiring multiple generations of contributors). (2) We evaluated projects with respect to their spatial extent, and categorized them somewhat arbitrarily as small $\left(0-100 \mathrm{~km}^{2}\right)$, medium $\left(100-1,000 \mathrm{~km}^{2}\right)$ or

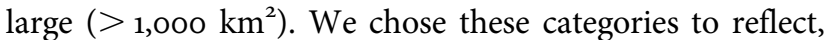
approximately, habitat fragments, parks, and ecosystems, respectively. (3) We estimated the annual budget of the project as small ( $<$ USD 100,000), medium (USD 100,000-1 million) or large ( $>$ USD 1 million). Typically, respondents did not provide this financial information; thus projects were categorized based on the scope of their activities, and these categories should be considered approximations. (4) We categorized projects based on the agencies that administered or funded the activities: globally empowered agencies (e.g. the UN or IUCN), national governments, state governments, international NGOs, national NGOs, universities, local organizations (e.g. community-based organizations), companies, private individuals and mixed strategies. (5) We categorized projects based on the conservation approach used: strict protection (which included eradication of invasive species and restoration), community conservation and development, education at the local level, efforts to gain knowledge to inform conservation, and research stations. These approaches are not mutually exclusive, nor were they intended to represent any ordinal scale; thus mixed strategies were also considered (e.g. protection combined with education at the local level, or community conservation and development combined with efforts to generate knowledge to inform conservation).

In tabulating responses we used a series of rules. (1) If two responses pertained to the same conservation project (i.e. same location/site and approach), we consolidated them into a single response, but we included non-redundant information from both responses. (2) If responses were provided from the same site, but if they described different approaches, we considered them to be individual responses. (3) We classified responses describing more than one approach as mixed efforts, which we considered a unique category. (4) We considered projects that were administered, funded or guided by multiple sources (e.g. national government and international NGO) to be mixed efforts. (5) If the administering body changed over time (e.g. private individuals organizing over time to become a local group or NGO), we only considered the original agency. If sufficient information to categorize a project was not provided in the original response, we sought literature or information from the Internet; only if such information was not available did we then e-mail the original respondent with specific questions.

To clarify definition(s) of success, we re-contacted a random sample of the original 66 respondents and obtained information about the attributes of success for $40 \%$ of the original 90 cases. We asked structured questions, including: whether respondents had a defined goal at the beginning of the efforts, whether those goals were specific (e.g. increase the population size of a specific species) or general (e.g. protect a park and its biodiversity through a variety of means), what was the basis on which success was considered to have been achieved, was success quantitatively assessed, and how was success evaluated.

\section{Results}

The majority (88\%) of the 90 projects perceived by respondents as being successful were long-term projects (i.e. $>10$ years). Ten percent of projects perceived as successful were short-term, and only $2 \%$ were medium-term. With respect to spatial scale, $52 \%$ were small scale, $38 \%$ were large scale and $10 \%$ were medium scale. Most projects $(68 \%)$ that respondents viewed as successful had relatively small annual budgets (i.e. $<$ USD 100,000), $21 \%$ had large annual budgets, and $11 \%$ had intermediate budgets.

The organizations in charge of projects perceived by the respondents as successful were diverse, with one third of projects involving more than one type of organization; of these, $90 \%$ involved two types of organizations, $7 \%$ involved three types, and $3 \%$ involved four types. International NGOs (26.4\% including mixed, 26.7 excluding mixed), universities (24.0\% including mixed, 23.3 excluding mixed), and national governments ( $20.7 \%$ including mixed, 20.0 excluding mixed) were the organizing bodies for the majority of projects perceived as successful ( $71 \%$ including mixed, $70 \%$ excluding mixed). Only three projects perceived as successful (four including mixed projects) involved a globally empowered agency, such as the UN (Fig. 1a). Similarly, private individuals $(1.7 \%$ including mixed, $2.0 \%$ excluding mixed) and companies (o.8\% including mixed, o\% excluding mixed) were rarely involved in projects perceived as successful. However, Internet-based information often suggested that individuals were instrumental in the 


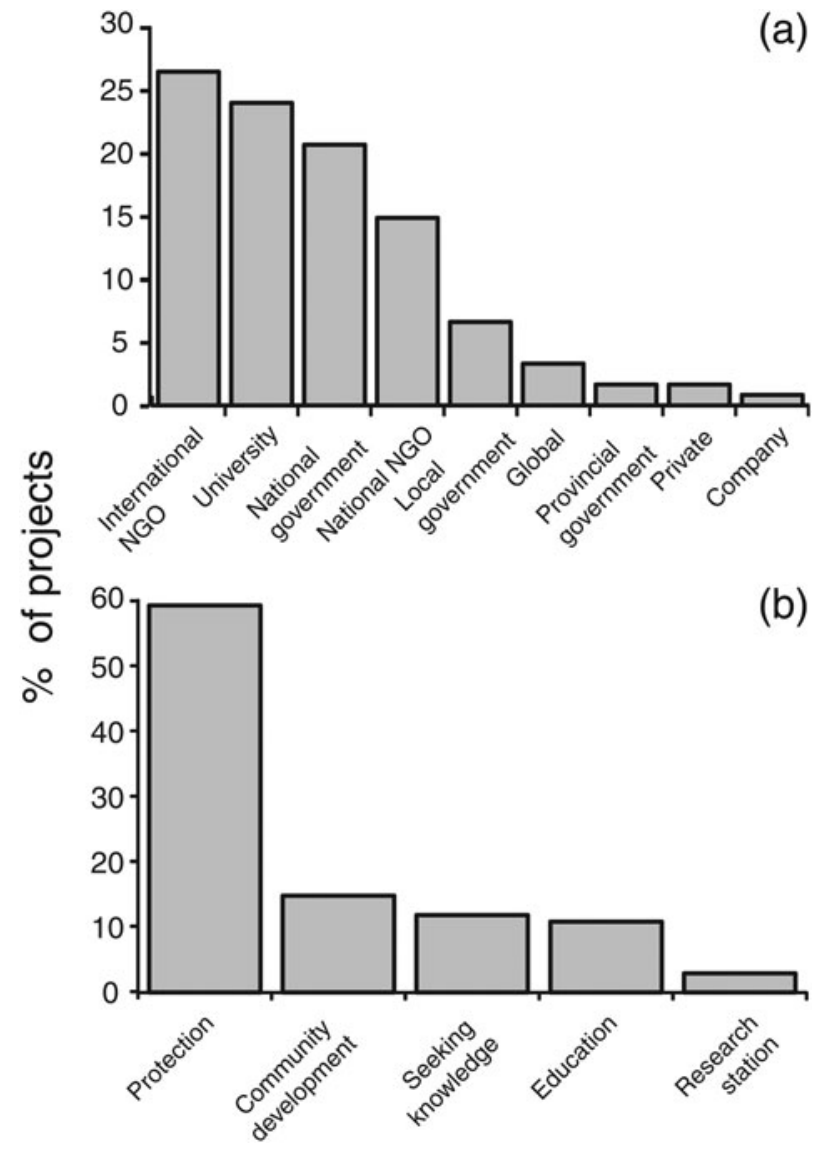

FIG. 1 (a) The nature of the organization in charge of what respondents perceived as being associated with successful conservation projects, and (b) the nature of the approach that respondents perceived as being associated with successful conservation projects. Projects involving a mix of organizations or strategies are included.

establishment of many successful conservation projects (Laurance, 2013). This occurs, for example, when individuals champion an effort.

The highest proportion of projects perceived as successful involved either protection alone $(64.9 \%)$ or protection in combination with another approach (59.4\%). Projects aimed at community development ranked the next highest when mixed projects were considered (14.9\%), but such community development projects ranked lower (7.8\%), after education (mixed 10.9\%, alone 14.3\%) and seeking knowledge (mixed $11.9 \%$, alone $10.9 \%$ ) when mixed projects were not considered (Fig. 1b). Projects involving the establishment of a research station (Struhsaker et al., 2005) ranked the lowest of the five approaches, both for singleapproach projects $(2.6 \%)$ and for multiple approach projects (3.0\%); this probably reflects the fact that this approach is seldom attempted and is rarely recognized as contributing to conservation (Struhsaker et al., 2005; Laurance, 2013).

All of the 36 conservation projects ( $40 \%$ of the 90 cases considered in the previous analyses) for which we obtained information on definitions of success stated that there was a set goal at the beginning of the effort. These goals ranged from very specific (e.g. protect a particular species, determine the genetic diversity of a species in a specific region, restore forest to an area, establish new environmental laws), to more general (e.g. decrease human-wildlife conflict, decrease poaching, promote education in neighbouring communities, protect biodiversity in general). $19.4 \%$ of projects were deemed successful simply because an event had occurred (e.g. a law was passed, a park or reserve was created, a fishery or bushmeat market was closed). For $36.1 \%$ of the projects, quantitative data about success were available (e.g. censuses demonstrated a population increase, measurements of land indicated that a specific number of hectares had been reforested, the rate of carnivore killing of livestock had decreased). A caveat is that these values do not have controls and we do not know what would happen in the absence of the intervention. However, for $63.9 \%$ of projects no evaluation was done and thus no quantitative data existed to evaluate success.

\section{Discussion}

Members of the conservation community perceived longterm, small-scale, relatively low-budget projects as most successful, especially when a protectionist approach was used, either alone or in combination with another approach. This information represents the impressions of the sample of respondents and thus their individual definitions of success, the frequency that an approach was used, the type of organization involved, the level and duration of funding, and other factors. Thus, our results do not provide an objective assessment of success but rather a picture of how the conservation community itself perceives success.

Over the last several decades the popularity of different conservation approaches has swung from purely protectionist approaches in the 1970s to sustainable development in the 1990s and back again (Robinson, 1993). If the success of a project can only be assessed over the long-term, and if protectionist programmes were some of the first conservation programmes, then perceptions of success may partially represent a historical bias towards protectionist approaches. Nevertheless, sustainable development has been promoted for more than 30 years. In fact, many of the respondents, including most of the authors of this study, were just starting their careers when sustainable development was being most strongly promoted.

The fact that projects perceived as successful were mostly long-term, small-scale, and low-budget probably reflects a combination of the dedication of conservationists, the tractability of conserving small areas of land, and the vagaries of funding. The value of such projects in international scientific collaborations has been recognized (NRC, 2011). 


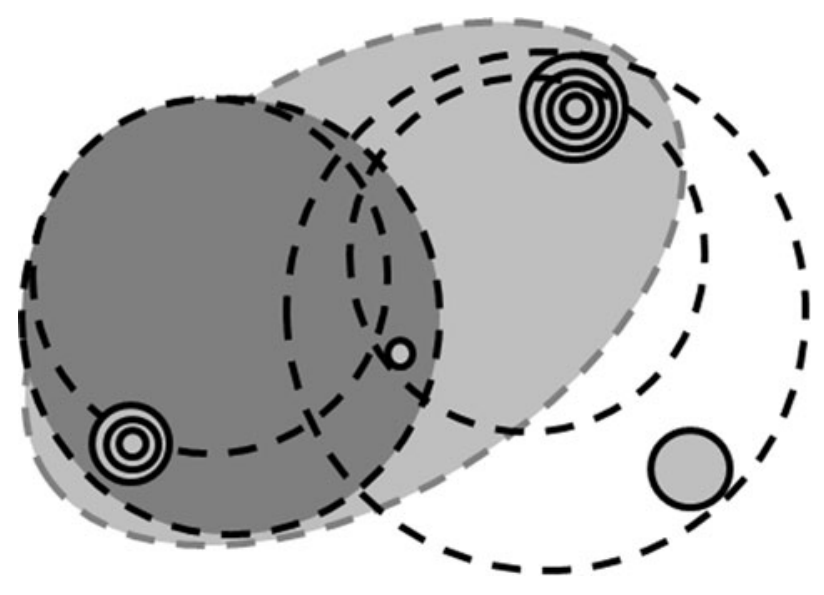

FIG. 2 Anchors for conservation networks. Long-term, small-scale conservation projects, shown with concentric circles representing each decade of the project, can serve as anchors for young projects, either by extending their influence (dark grey background) or by providing connectivity (white background). Ultimately, connectivity among small-scale projects can result in large-scale influence (light grey background).

However, some of the most important conservation efforts must occur at large scales and are only feasible with large monetary investments. Such efforts include global conservation initiatives associated with marine fisheries (Garcia \& Grainger, 2005) and climate change (Hannah et al., 2002; Lovett et al., 2005; IPCC, 2007).

Ultimately, it is not our intention to advocate one approach over another. However, our analysis offers some general hypotheses for conservation planning. For example, when it is possible to reach conservation goals by operating at small spatial scales (i.e. $<100 \mathrm{~km}^{2}$ ), agencies should consider providing long-term funding at relatively low levels. This approach is likely to be more effective than the boom-and-bust cycles typical of large-scale initiatives. Similarly, projects that adopt a protectionist approach, either alone or in combination with other approaches, are perceived as frequently being associated with success. Our results also suggest that long-term, small-scale, relatively inexpensive projects could serve as anchors for new, similarly small-scale and inexpensive initiatives. Linking long-term successful projects with new or younger ones could lead to 'conservation contagion' (Horwich et al., 2013), essentially enhancing the scope of conservation efforts with only additive (vs multiplicative) costs (Fig. 2).

Overall, our data show that a variety of approaches are perceived as successful when applied judiciously. Small-scale, long-term efforts, often spearheaded by single individuals, may add considerably to the arsenal of programmes brought to bear on the complex problem of natural resources protection in the developing world. As human populations continue to expand, per capita resource use rises, forest resources in the tropics continue to decline, climate changes more rapidly, freshwater and marine resources are overexploited, and infectious diseases continue to emerge, increasingly successful efforts will be needed. Our data provide a glimpse into what the conservation community itself perceives as being successful, and perhaps the beginning of a roadmap for designing and implementing successful efforts.

\section{Acknowledgements}

Funding for the research was provided by the Canada Research Chairs Program, Natural Science and Engineering Research Council of Canada, Infectious Disease Programme, and the UK Economic and Social Research Council. We thank John Oates, Tom Struhsaker, Valerie Schoof and Tyler Bonnell for helpful comments. We would like to give special thanks to all the people who contributed their stories to our project.

\section{References}

Andam, K.S., Ferraro, P.J., Pfaff, A., Sanchez-Azofeifa, G.A. \& Robalino, J.A. (2008) Measuring the effectiveness of protected area networks in reducing deforestation. Proceedings of the National Academy of Sciences of the United States of America, 105, 1608916094.

Bates, L.A. \& Byrne, R.W. (2007) Creative or created: using anecdotes to investigate animal cognition. Methods, 42, 12-21.

BeEVer, E. (2000) The roles of optimism in conservation biology. Conservation Biology, 14, 907-909.

Bruner, A.G., Gullison, R.E., Rice, R.E. \& da Fonseca, G.A.B. (2001) Effectiveness of parks in protecting tropical biodiversity. Science, 291, 125-128.

Butchart, S.H.M., Walpole, M., Collen, B., van Strien, A., Scharlemann, J.P.W., Almond, R.E.A. et al. (2010) Global biodiversity: indicators of recent declines. Science, 328, 1164-1168.

Chapman, C.A. \& Peres, C.A. (2001) Primate conservation in the new millennium: the role of scientists. Evolutionary Anthropology, 10, 16-33.

Curran, L.M., Trigg, S.N., McDonald, A.K., Astiani, D., Hardiono, Y.M., Siregar, P. et al. (2004) Lowland forest loss in protected areas of Indonesian Borneo. Science, 303, 1000-1003.

FAO (2010) The Global Forest Resource Assessment 2010. Food and Agriculture Organization of the United Nations, Rome, Italy.

Garcia, S.M. \& Grainger, R.J.R. (2005) Gloom and doom? The future of marine capture fisheries. Philosophical Transactions of the Royal Society B, 360, 21-46.

Garnett, S.T. \& Lindenmayer, D.B. (2011) Conservation science must engender hope to succeed. Trends in Ecology \& Evolution, 26, 59-60.

Hannah, L., Midgley, G.F., Lovejoy, T., Bond, W.J., Bush, M., Lovet T, J.C. et al. (2002) Conservation of biodiversity in a changing climate. Conservation Biology, 16, 264-268.

Hartter, J., Ryan, S.J., Southworth, J. \& Chapman, C.A. (2011) Landscapes as continuous entities: forest disturbance and recovery in the Albertine Rift landscape. Landscape Ecology, 26, 877-89o. 
Horwich, R.H., DAs, R. \& Bose, A. (2013) Conservation and current status of the golden langur in Assam, India, with reference to Bhutan. Primate Conservation, 27, 77-83.

IPCC (2007) Climate Change 2007: Synthesis Report. Intergovernmental Panel on Climate Change, Geneva, Switzerland.

Jackson, J.B.C., Kirby, M.X., Berger, W.H., Bjorndal, K.A., Botsford, L.W., Bourque, B.J. et al. (2001) Historical overfishing and the recent collapse of coastal ecosystems. Science, 293, 629-637.

Joppa, L.N., Loarie, S.R. \& Pimm, S.L. (2008) On the protection of "protected areas". Proceedings of the National Academy of Sciences of the United States of America, 105, 6673-6678.

Joppa, L.N. \& PFAFF, A. (2009) High and far: biases in the location of protected areas. PLoS One, 4(12), e8273.

Joppa, L.N. \& PFAFF, A. (2010) Reassessing the forest impacts of protection: the challenge of nonrandom location and a corrective method. Annals of the New York Academy of Sciences, 1185, 135-149.

Kapos, V., Balmford, A., Aveling, R., Bubb, P., Carey, P., Entwistle, A. et al. (2008) Calibrating conservation: new tools for measuring success. Conservation Letters, 1, 155-164.

Kapos, V., Balmford, A., Aveling, R., Bubb, P., Carey, P., Entwistle, A. et al. (2009) Outcomes, not implementation, predict conservation success. Oryx, 43, 336-342.

Laurance, W.F. (2013) Does research help to safeguard protected areas? Trends in Ecology \& Evolution, 28, 261-266.

Laurance, W.F., Useche, D.C., Rendeiro, J., Kalka, M., Bradshaw, C.J.A., SlOAN, S.P. et al. (2012) Averting biodiversity collapse in tropical forest protected areas. Nature, 489, 290-294.

LiU, J.G., Linderman, M., OUYAnG, Z.Y., An, L., YANG, J. \& ZHAnG, H.M. (2001) Ecological degradation in protected areas: the case of Wolong Nature Reserve for giant pandas. Science, 292, 98-101.

Lovett, J.C., Midgley, G.F. \& Barnard, P. (2005) Climate change and ecology in Africa. African Journal of Ecology, 43, 167-169.

McClenachan, L., Ferretti, F. \& Baum, J.K. (2012) From archives to conservation: why historical data are needed to set baselines for marine animals and ecosystems. Conservation Letters, 5, 349-359.

Novace K, M.J. (2008) Engaging the public in biodiversity issues. Proceedings of the National Academy of Sciences of the United States of America, 105, 11571-11578.

NRC (National Research Council) (2011) U.S. and International Perspectives on Global Science Policy and Science Diplomacy: Report of a Workshop. The National Academies Press, Washington, DC, USA.

OAtEs, J.F. (1996) Habitat alteration, hunting and the conservation of folivorous primates in African forests. Australian Journal of Ecology, 21, 1-9.

Oliveira, P.J.C., Asner, G.P., Knapp, D.E., Almeyda, A., Galván-Gildemeister, R., Keene, S. et al. (2007)
Land-use allocation protects the Peruvian Amazon. Science, 317, 1233-1236.

Rands, M.R.W., Adams, W.M., Bennun, L., Butchart, S.H.M., Clements, A., Coomes, D. et al. (2010) Biodiversity conservation: challenges beyond 2010. Science, 329, 1298-1303.

Robinson, J.G. (1993) The limits to caring: sustainable living and the loss of biodiversity. Conservation Biology, 7, 20-28.

Rodrigues, A.S.L., AkÇakaya, H.R., Andelman, S.J., BaKarr, M.I., Boitani, L., BROOKs, T.M. et al. (2004) Global gap analysis: priority regions for expanding the global protected-area network. BioScience, 54, 1092-1100.

Román-Cuesta, R.M. \& Martínez-Vilalta, J. (2006)

Effectiveness of protected areas in mitigating fire within their boundaries: case study of Chiapas, Mexico. Conservation Biology, 20, 1074-1086.

Smith, T.B., Bruford, M.W. \& Wayne, R.K. (1993) The preservation of process: the missing element of conservation programs. Biodiversity Letters, 1, 164-167.

Solomon, J.N. (2007) An Evaluation of Collaborative Resource Management and the Measurement of Illegal Resource Use in a Ugandan National Park. PhD thesis. University of Florida, Gainesville, USA.

Struhsaker, T.T., Struhsaker, P.J. \& Siex, K.S. (2005) Conserving Africa's rain forests: problems in protected areas and possible solutions. Biological Conservation, 123, 45-54.

\section{Biographical sketches}

Colin Chapman is interested in how nutrition, disease, stress, climate change and social factors interact to influence mammal abundance, and works with local communities on conservation and community well-being. Anneke DeLuycker specializes in the ecology, behaviour and conservation of primates. RAFAEL RE YNA - H URT A D O has studied movement of social animals in tropical habitats, especially ungulates and wild pigs. JUAN CARLOS SERIO-SILVA's interests are in ecology, behaviour and conservation of Mexican primates, and in increasing the effectiveness of conservation. Тномаs Sмiтн investigates how biodiversity is generated and maintained, and also focuses on evolution in human-altered environments, the ecology of disease, and new approaches for mapping adaptive variation in species. KAREN STRIER is interested in understanding the behavioural ecology of primates from a comparative perspective and in applying these perspectives to conservation. TONY GOLDBERG's research focuses on the ecology, epidemiology and evolution of viral disease, and studies how pathogens are transmitted among hosts, across complex landscapes and over time. 